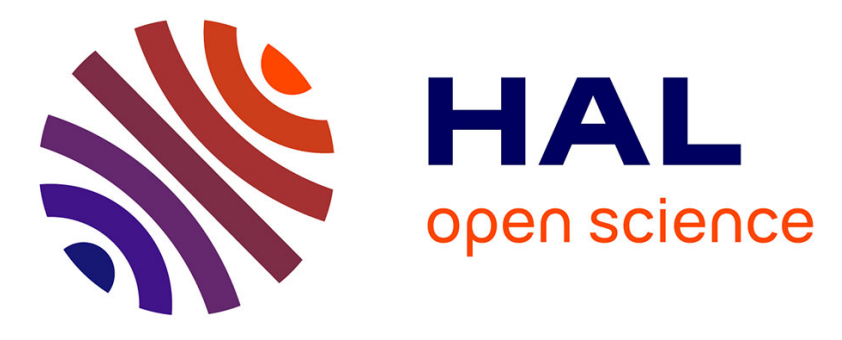

\title{
Appropriateness of admission and days of stay in pediatric hospital in Ancona, Italy
}

Daniela Vincitorio, Giacomina Chiaradia, Chiara Waure, Jerome Mastaki Kambale, Giuseppe Torre, Francesco Stanislao

\section{- To cite this version:}

Daniela Vincitorio, Giacomina Chiaradia, Chiara Waure, Jerome Mastaki Kambale, Giuseppe Torre, et al.. Appropriateness of admission and days of stay in pediatric hospital in Ancona, Italy. Journal of Public Health, 2010, 18 (5), pp.497-503. 10.1007/s10389-010-0325-y . hal-00521548

\author{
HAL Id: hal-00521548 \\ https://hal.science/hal-00521548
}

Submitted on 28 Sep 2010

HAL is a multi-disciplinary open access archive for the deposit and dissemination of scientific research documents, whether they are published or not. The documents may come from teaching and research institutions in France or abroad, or from public or private research centers.
L'archive ouverte pluridisciplinaire HAL, est destinée au dépôt et à la diffusion de documents scientifiques de niveau recherche, publiés ou non, émanant des établissements d'enseignement et de recherche français ou étrangers, des laboratoires publics ou privés. 
Editorial Manager(tm) for Journal of Public Health Manuscript Draft

Manuscript Number: JOPH-D-09-00044R2

Title: Appropriateness of admission and day of stay in pediatric hospital in Ancona, Italy

Article Type: Original Article

Corresponding Author: Dr Chiara de Waure,

Corresponding Author's Institution: Catholic University of the Sacred Heart

First Author: Daniela Vincitorio

Order of Authors: Daniela Vincitorio; Giacomina Chiaradia; Chiara de Waure; Jerome Mastaki Kambale; Giuseppe La Torre; Francesco Di Stanislao

Abstract: Background. In Italy, hospital admissions costs account for nearly $42 \%$ of total health expenditure; in the Marche region, this share exceeds 50\%. High costs of hospitalisation can be, however, partly explained by inappropriate use. The aim of this research was to assess the risk factors associated with inappropriate hospital admissions and stay for acute pediatric patients.

Methods. Clinical records of children from 30 days to 14 years of age admitted to the wards of orthopaedics, pediatrics, pediatric isolation, pediatric surgery and pediatric oncohaematology at Salesi Pediatric Hospital of Ancona throughout 2004 were reviewed. The Italian Pediatric Appropriateness Evaluation Protocol (PRUO) was used as a tool for assessing inappropriateness of admission and days of stay.

Results. Overall $21.7 \%(95 \% \mathrm{CI}=16.1 \%-22.4 \%)$ of hospital admissions and $30.3 \%$ (95\%CI= 26.0\%$34.9 \%$ ) of days of stay were judged to be inappropriate. Multiple logistic regression analysis indicated that inappropriate admission was significantly associated with type of admission, discharge ward and place of residence. Inappropriateness of stay was significantly higher if admission was to a medical ward and if admission itself was judged inappropriate.

Conclusions. In a socioeconomic context in which reducing waste is necessary, ineffective health care interventions are no longer tolerable. As a tool capable of integrating each patient's specific features with those of the health care process, the pediatric PRUO could be a valid tool in the hands of managers for monitoring the appropriateness of admission and stay.

Response to Reviewers: Reviewers' comments:

Reviewer \#1: I suggest to evaluate the possibility to insert in the introduction this recent reference: Poppa G, La Torre G, Mannocci A, Specchia ML, Rabacchi G, Vaschetto C, Ricciardi W, Boccia A. Appropriateness of admission and stay in obstetrics wards: a new tool assessing unnecessary days of hospital care. Ital J Public Health 2009; 4: 51-56.

According to the Reviewer's suggestion, the reference has been inserted in the introduction of the manuscript.

Reviewer \#3: As already stated, the topic is very interesting and relevant to Public health. Though the corrections made by the Authors following the reviewers' recommendations have made some points clearer, the quality of English used, according to me, is not yet up to standards; some 
grammatical review is still needed and this could be the reason why some paragraphs are still not clear especially in the Discussion.

According to the Reviewer's observation, the English has been completely checked in order to improve the clearness of the manuscript and review the grammar. 


\section{ANSWERS POINT BY POINT}

Reviewers' comments:

Reviewer \#1: I suggest to evaluate the possibility to insert in the introduction this recent reference: Poppa G, La Torre G, Mannocci A, Specchia ML, Rabacchi G, Vaschetto C, Ricciardi W, Boccia A. Appropriateness of admission and stay in obstetrics wards: a new tool assessing unnecessary days of hospital care. Ital J Public Health 2009; 4: 51-56.

According to the Reviewer's suggestion, the reference has been inserted in the introduction of the manuscript.

Reviewer \#3: As already stated, the topic is very interesting and relevant to Public health. Though the corrections made by the Authors following the reviewers' recommendations have made some points clearer, the quality of English used, according to me, is not yet up to standards; some grammatical review is still needed and this could be the reason why some paragraphs are still not clear especially in the Discussion.

According to the Reviewer's observation, the English has been completely checked in order to improve the clearness of the manuscript and review the grammar. 
Authors: Daniela Vincitorio ${ }^{1}$, Giacomina Chiaradia ${ }^{2}$, Chiara de Waure ${ }^{2}$, Jerome Mastaki Kambale $^{1}$, Giuseppe La Torre ${ }^{2-3}$, Francesco Di Stanislao ${ }^{1}$

Affiliations: ${ }^{1}$ School of Hygiene and Preventive Medicine, Polytechnic University of Marche (Italy); ${ }^{2}$ Epidemiology and Biostatistics Unit, Institute of Hygiene, Catholic University of the Sacred Heart, Rome; ${ }^{3}$ Clinical Medicine and Public Health Unit Sapienza University of Rome.

\section{Address of correspondence:}

Chiara de Waure, MD, MPH

Institute of Hygiene

Catholic University of the Sacred Heart

L.go F. Vito 1, 00168 Rome

E-mail: chiaradw@alice.it

Tel: +39.6 .35001525$

Fax: +39.6 .35001522$ 


\begin{abstract}
Background. In Italy, hospital admissions costs account for nearly $42 \%$ of total health expenditure; in the Marche region, this share exceeds 50\%. High costs of hospitalisation can be, however, partly explained by inappropriate use. The aim of this research was to assess the risk factors associated with inappropriate hospital admissions and stay for acute pediatric patients.
\end{abstract}

Methods. Clinical records of children from 30 days to 14 years of age admitted to the wards of orthopaedics, pediatrics, pediatric isolation, pediatric surgery and pediatric oncohaematology at Salesi Pediatric Hospital of Ancona throughout 2004 were reviewed. The Italian Pediatric Appropriateness Evaluation Protocol (PRUO) was used as a tool for assessing inappropriateness of admission and days of stay.

Results. Overall $21.7 \%(95 \% \mathrm{CI}=16.1 \%-22.4 \%)$ of hospital admissions and $30.3 \%(95 \% \mathrm{CI}=$ $26.0 \%-34.9 \%$ ) of days of stay were judged to be inappropriate. Multiple logistic regression analysis indicated that inappropriate admission was significantly associated with type of admission, discharge ward and place of residence. Inappropriateness of stay was significantly higher if admission was to a medical ward and if admission itself was judged inappropriate.

Conclusions. In a socioeconomic context in which reducing waste is necessary, ineffective health care interventions are no longer tolerable. As a tool capable of integrating each patient's specific features with those of the health care process, the pediatric PRUO could be a valid tool in the hands of managers for monitoring the appropriateness of admission and stay.

Keywords: appropriateness, pediatric, hospitalisation, days of stay 


\section{Introduction}

In Italy, hospital admissions alone account for nearly $42 \%$ of total health expenditure of the public sector, compared to the OECD average of 35\%. In the Marche region, this share exceeds $50 \%$. Available data indicate a pediatric hospitalisation rate of $103.6 \%$ and $161 \%$ nationally and in Marche, respectively (Bianco et al. 2003). High costs of hospitalisation can be partly explained by inappropriate hospital use, defined as inadequate timing or type of care. Appropriateness of admission can therefore be considered as an important criterion for evaluating the adequate use of resources in the health sector and an important component of the quality process assessment (Angelillo et al. 2000, Siliquini et al. 2005).

Several international studies showed that a not negligible proportion of hospital care should be considered inappropriate (Kemper 1988; Waldrop et al. 1998; Esmail et al. 2000; Katz et al. 2001); some efforts have also been made to develop new tools for the evaluation of the appropriateness in specific settings, such as obstetrics (Poppa et al. 2009). However, few published studies on the appropriateness of pediatric admissions in Italy are available (Bianco et al. 2003; Chiaradia et al. 2008).

In Italy, as in some other countries, legislative authorities have adopted appropriateness as a condition for rationalising the allocation of economic resources. The modernisation of the Italian National Health System (SSN) (Legislative Decree (D.Lgs) n. 502 1992), which converted public hospitals into enterprises with organisational and managerial autonomy, has naturally led to the integration of the concept of appropriateness into programmatic and organisational documents (subsequent National Health Plans, D.Lgs 2291999 and Decree of the President of the Council of Ministers (DPCM) 29/11/2001). This decision implied the adoption of objective methods for the evaluation of the appropriateness of admissions and days of stay. Several such tools have been developed: the Intensity of service, the Severity of illness, the Discharge screens (ISD) set of criteria (The InterQual review system 1996), the 
Appropriateness Evaluation Protocol (AEP) (Gertman and Restuccia 1981) and the Managed among the most commonly used. They consist of diagnosis-independent sets of criteria, related to the severity of illness and required services, which must be fulfilled to ensure appropriateness. One of the tools used in Italy to evaluate the appropriateness of hospitalisation is the PRUO (Protocol for hospital use revision), the Italian version of the American AEP (Appropriateness Evaluation Protocol developed by Gertman PM and Restuccia JD, 1981). Just like the AEP, the PRUO has been revised and adapted to specific settings (pediatric wards; day hospital) (Ministerial Project "Development and evaluation of tools to promote an appropriate acute hospital use).

The aim of our work was to assess the prevalence of inappropriate admissions and days of stay in acute pediatric patients and identify the associated risk factors.

\section{Methods}

\section{Study population}

A retrospective cross-sectional study was carried out to assess the inappropriateness of admission and days of stay and the associated risk factors. A sample of clinical records of children, aged 30 days to 14 years, admitted to Salesi Pediatric Hospital of Ancona in 2004 was reviewed. Sixteen randomly selected days (indicated as index days) were considered to identify records to be reviewed. In order to avoid seasonal influences, four days for each season were selected. All clinical records for each selected day were examined and reviewers analysed both the admissions and the day of stay recorded in the index day. As required by the Pediatric PRUO (Ministerial Project "Development and evaluation of tools to promote an appropriate acute hospital use"), clinical records of patients admitted to Day-Hospital, One day Hospital, Day-Surgery and One day Surgery were excluded from the sample as well as 
those of children admitted to pediatric intensive care unit (ICU), pediatric sub ICU, neonatology and infantile neuropsychiatry because they did not meet the inclusion criteria defined by the PRUO itself.

We included in the study clinical charts of children admitted to the following medical and surgical wards: orthopedics, pediatrics, pediatric isolation, pediatric surgery, and pediatric oncohaematology.

For each clinical chart, data concerning demographic characteristics of patient and hospitalisation details (type of admission, ward, date and hour of admission, discharge date, diagnosis related group (DRG)) were collected and recorded. As regards DRG, it is a system to classify hospital cases into groups expected to have a similar use of hospital resources, developed for a prospective payment system. The Italian Government used the DRG classification to evaluate the appropriateness of procedures, by labelling a number of DRGs as “at risk of inappropriateness" (DPCM 29/11/2001).

\section{Search tool}

The pediatric PRUO (Ministerial Project "Development and evaluation of tools to promote an appropriate acute hospital use") was used to assess the appropriateness of admissions and days of stay. Like AEP, PRUO provides a number of criteria to be met in order for the hospitalisation to be considered as appropriate. Two different lists of criteria exist, one for the appropriateness of admission and the other for the appropriateness of stay.

Criteria for appropriateness of admission are grouped into two subsets, one focusing on the conditions of the patient (consisting of 11 items) and one on nursing/life support services (7 items). Criteria for appropriateness of stay are divided into 3 groups, related to the need for medical services (11), the nursing/life support services (7), and the conditions of the patient (9) respectively. Admission and days of stay were determined to be appropriate if at least 1 
criterion was met; otherwise, they were considered inappropriate. The protocol was applied independently by two different researchers.

\section{Statistical analysis}

Univariate analysis (Chi square and Mann Whitney tests) was first performed to assess associations between explanatory variables and our two outcomes of interest: inappropriateness of admission and of days of stay.

A stepwise multiple logistic regression with backward elimination procedure was then performed. In the regression models, variables likely to be associated with inappropriateness of admission (model 1) and inappropriateness of days of stay (model 2) with a $p<0.25$ at the univariate analysis were included, as described by Hosmer and Lemeshow (Hosmer and Lemeshow 1989). Thus, the following explanatory variables were put into the models: patient age, patient sex, country of residence, ward of admission, type of admission, season of admission, DRG, day of the week of admission (only for model 1), day of the week of inpatient stay and admission inappropriateness (only for model 2). The model goodness of fit was tested by the Hosmer and Lemeshow test.

The results are presented as odds ratios (OR) and 95\% confidence intervals $(95 \% \mathrm{CI})$. Significant level was set at $\mathrm{p}<0.05$. Data were analysed using the SPSS statistic software, release 12.0 .

\section{Results}

Four hundred and twenty nine clinical admission charts in Salesi Pediatric Hospital- Ancona were checked; sample characteristics are described in table 1.

The sample mean age was 4.69 years and $273(63.6 \%)$ patients were males. The mean duration of hospital stay was 9.27 days. 
The total number of inappropriate admissions was $93(21.7 \%, 95 \% \mathrm{CI}=16.1 \%-22.4 \%)$, whereas the inappropriate stays were $130(30.3 \%, 95 \% \mathrm{CI}=26.0 \%-34.9 \%)$ (table 1$)$. Inappropriateness of admission (table 2$)$ was associated with patient age $(\mathrm{p}=0.046)$, residence $(\mathrm{p}=0.032)$, planned admission $(\mathrm{p}=0.016)$, time of admission $(\mathrm{p}=0.043)$ and discharge ward $(\mathrm{p}=0.001)$.

Inappropriateness of days of stay (table 2) was associated with patient age $(p=0.026)$, discharge ward $(\mathrm{p}<0.0001)$, duration of hospitalisation $(\mathrm{p}=0.002)$, inappropriateness of admission $(\mathrm{p}<0.0001)$ and, finally, DRGs "not at risk of inappropriateness" as defined in the document 2C of Italian Government 29/11/2001 decree ( $\mathrm{p}=0.001)$.

Results of the logistic multivariate analysis are shown in table 3. The risk of inappropriateness of admission appeared to be significantly associated with: elective admission type $(\mathrm{OR}=2.47$, 95\% $\mathrm{CI}=1.39-4.39)$; medical dismissal unit $(\mathrm{OR}=4.01,95 \% \mathrm{CI}=2.33-6.91)$; residence outside the city and province of Ancona $(\mathrm{OR}=1.89,95 \% \mathrm{CI}=1.19-3.10)$.

The following significant associations were found in the analysis of inappropriateness of days of stay (table 3): admission to a medical ward $(\mathrm{OR}=3.04,95 \% \mathrm{CI}=1.74-5.31)$; increasing duration of hospitalisation $(\mathrm{OR}=1.04,95 \% \mathrm{CI}=1.01-1.07)$; inappropriateness of admission $(\mathrm{OR}=29.23,95 \% \mathrm{CI}=14.86-57.47)$; hospitalisation with DRGs considered "not at risk of inappropriateness" by the Italian Government $(\mathrm{OR}=1.49,95 \% \mathrm{CI}=1.08-1.67)$. The overall regression models were demonstrated to be statistically significant ( $\mathrm{p}<0.001$ for both models); moreover, Hosmer and Lemeshow test resulted 0.761 and 0.202 in model 1 and 2, respectively.

Hospitalisations in DRGs "at risk of inappropriateness" appeared to have half the mean length of those in DRGs "not at risk of inappropriateness" (4.21 (Standard Deviation (SD): 4.15) vs 10.03 (SD: 38.87)). 


\section{Discussion}

Several studies and scientific works on appropriateness evaluation tools exist in literature, but few have pediatric hospitalisations as their main subject. At the level of health systems, both similarities and differences between Italy and other countries can be appreciated, with our system providing universal coverage free of charge at the point of service. In the United Kingdom, despite the growth of user charges in some areas, most primary and secondary health care is still provided free of charge; in Canada, the system is publicly financed, but privately delivered; in the United States, individuals are responsible for meeting most health costs (Bianco et al. 2003). Such differences in the organisation of health care systems imply that the rates of inappropriate hospital use in different countries may not be directly comparable; however, there is some evidence that a better level of primary care services is associated with lower hospitalisation of children (Perrin et al. 1989).

Bindman et al. (1995) suggested that there is a relationship between perceived better access to health services and lower hospitalisation rates for conditions preventable by adequate ambulatory care. In addition, paediatricians may play an important role in improving the quality and the efficiency of health care, by more closely monitoring the circumstances of the children at home and by hospitalising patients only when necessary. The proportion of inappropriateness of admission, as obtained from the sample, was $21.7 \%$ (95\% $\mathrm{CI}=16.1 \%$ $22.4 \%$ ) while that of days of stay was $30.3 \%(95 \% \mathrm{CI}=26.0 \%-34.9 \%)$; these results are similar to those found in international literature: $20-28 \%$ in Spain, $10.5-29 \%$ in USA, $29-22 \%$ in Canada, 19-28\% in England, 24-19\% in Australia (Perrin et al. 1989; Oterino et al. 1999; Smith et al. 1993; Formby et al. 1991) for admission and days of stay respectively. Finally, it appears that planned admissions to hospital are more likely to be inappropriate than admissions under emergency circumstances, probably because of the lower complexity of care needed. Accordingly, patients hospitalised under non-emergency circumstances could be 
better managed in settings other than the hospital. Lastly, consistently with the results of other of admission could be explained by the fact that non-resident patients admitted to Regional Hospitals are those planned a priori and therefore, as explained above, at higher risk of inappropriateness. Being a resident of a district different from the one of the hospital is a risk factor for inappropriateness of admission.

The association between admission ward and inappropriateness of hospitalisation can be explained, as suggested by other studies (Gloor et al. 1993), by the low complexity of care content of medical hospitalisations compared to surgical ones; this is confirmed by the increased risk of inappropriateness of stay when admissions were inappropriate in the first place. An increase in the length of hospital stay is also a risk for inappropriateness, which suggests that this parameter is not an indicator of clinical complexity. An unexpected finding is the association between the outcome "inappropriateness of days of stay" and the DRGs "not at risk of inappropriateness": the latter appeared to be at higher risk for inappropriateness of stay than the DRGs deemed "at risk of inappropriateness". However, it should be noted that the mean length of hospitalisations in DRGs "at risk of inappropriateness" was half the length of the others.

This study presents some limitations and some strengths. As regards limitations, the study design, a cross-sectional one, in which data about exposures of interest and outcomes are retrieved at the same time, could hamper the study of causality. Still, the vast majority of the studies conducted on the same topic adopted this design and proved to be able to detect associations between some factors and the outcomes. As far as the strengths are concerned, this study represents the first one conducted in the Marche Region, and one of the few Italian studies focusing on this particular issue. Moreover, it is also part of a currently ongoing multicenter study. 
In a socioeconomic context in which reducing waste is necessary, health care interventions not demonstrated to be effective or being completely ineffective should not be permitted. As a tool capable of integrating the specific characteristics of the patient with the features of the health care process, PRUO can be considered a valid tool in the hands of managers for monitoring hospital use. Even if the retrospective approach limits somewhat the value of the information gathered in this study, the tool remains useful for future studies on how to adapt healthcare to the specific conditions of each patient in an integrated approach.

\section{Acknowledgement}

We would like to thank Luca Valerio for his valuable linguistic revision of the manuscript.

\section{Conflict of Interest statement}

Authors declare to have no conflict of interest.

\section{References}

Angelillo IF, Ricciardi G, Nante N et al (2000) Appropriateness of hospital utilisation in Italy. Public Health 114(1):9-14.

Bianco A, Pileggi C, Trani F, Angelillo IF (2003) Appropriateness of admissions and days of stay in pediatric wards of Italy. Pediatrics 112:124-8.

Bindman AB, Grumbach K, Osmond D, et al (1995) Preventable hospitalisations and access to health care. JAMA 274(4):305-11.

Chiaradia G, de Waure C, La Torre G, Paparatti M, Ricciardi W (2008) Appropriateness of admission and hospital stay in pediatric wards: the case of a teaching hospital in Rome. Ann Ig 20(1):17-27 (in Italian). 
Decreto del Presidente del Consiglio dei Ministri. Definizione dei livelli essenziali di assistenza. 29 novembre 2001 (Decree of the President of the Council of Ministers. Definition of essential services level. November $\left.29^{\text {th }} 2001\right)$.

Decreto Legislativo 229/99. Norme per la razionalizzazione del Servizio sanitario nazionale. 19 giugno 1999 (Legislative Decree n. 229/99. Rules to rationalise National Health Service). Decreto Legislativo n. 502. Riordino della disciplina in materia sanitaria. 30 dicembre 1992 (Legislative Decree n. 502. Health discipline reform December $30^{\text {th }} 1992$ ).

Esmail A, Quayle JA, Roberts C (2000) Assessing the appropriateness of paediatric hospital admissions in the United Kingdom. J Public Health Med 22:231-8.

Formby DJ, Mc Mullin ND, Danagher K, Oldham DR (1991) The Appropriateness Evaluation Protocol: Application in an Australian children's hospital. Aus Clin Rev 11:12331.

Gertman PM, Restuccia JD (1981) The appropriateness evaluation protocol: a technique for assessing unnecessary days of hospital care. Med Care 19:855-71.

Gloor JE, Kissoon N, Joubert GI (1993) Appropriateness of hospitalisation in a Canadian pediatric hospital. Pediatrics 91:70-4.

Hosmer DW, Lemeshow S (1989) Applied logistic regression. New York, Wiley \& Sons.

Katz M, Warshawssky SS, Porat A, Press J (2001) Appropriateness of pediatric admissions to a tertiary care facility in Israel. Isr Med Assoc 3:501-3.

Kemper KJ (1988) Medically inappropriate hospital use in a pediatric population. N Engl J Med 318:1033-7.

Oterino D, Martínez A, González Fouces I, Peiró S (1999) Is it necessary to hospitalize so many children for so many days? Unnecessary pediatric hospitalisation. Ann Esp Pediatr 50:373-378 (in Spanish). 
Perrin JM, Homer CJ, Berwick DM (1989) Variation in rates of hospitalisation of children in three urban communities. N Engl J Med 320:1183-7.

Poppa G, La Torre G, Mannocci A, et al (2009). Appropriateness of admission and stay in obstetrics wards: a new tool assessing unnecessary days of hospital care. Ital J Public Health $6(4): 341-51$.

Progetto ministeriale "concettualizzazione, sviluppo e valutazione di strumenti di osservazione e di intervento che aumentino l'uso appropriato dell'ospedale per acuti" (Ministerial Project "Development and evaluation of tools to promote an appropriate acute hospital use). [cited 2009 July 13]. Available from: http://www.sanita.fvg.it/ars/specializza/programmi/covegno/Manuals.htm.

Siliquini R, Rocca N, Rocca G, Minniti D, Gianino MM, Renga G (2005) Understanding inappropriate hospital admissions of patients presenting to the Emergency Department. Ital J Public Health 2(2):33-411.

Smith HE, Sheps S, Matheson DS (1993) Assessing the utilization of in-patient facilities in a Canadian pediatric hospital. Pediatrics 92:587-93.

The InterQual review system. Marlborough (MA): InterQual Products Group;1996.

The Managed Care Appropriateness Protocol. Wellesley (MA): Oak Group;1996

Waldrop R, Peck GQ, Hutchinson S, Randall Z (1998) Comparison of pediatric hospitalisation using the Pediatric Appropriateness Evaluation Protocol at three diverse hospitals in Louisiana. J La State Med Soc 150:211-7. 
Table 1. Study population characteristics

\begin{tabular}{|c|c|c|}
\hline Characteristics & $\mathbf{N}$ & $\%$ \\
\hline \multicolumn{3}{|l|}{ SEX } \\
\hline Male & 273 & 63.6 \\
\hline Female & 156 & 36.4 \\
\hline \multicolumn{3}{|l|}{ AGE GROUP (year) } \\
\hline$<1$ & 96 & 22.4 \\
\hline $1-2$ & 114 & 26.6 \\
\hline $3-5$ & 86 & 20.5 \\
\hline $6-11$ & 70 & 16.3 \\
\hline$>11$ & 63 & 14.7 \\
\hline \multicolumn{3}{|l|}{ PLACE OF RESIDENCE } \\
\hline Ancona and province & 179 & 41.7 \\
\hline Marche region excluded Ancona and province & 185 & 43.1 \\
\hline Outside Marche region (with patients of foreign nationality) & 65 & 15.1 \\
\hline \multicolumn{3}{|l|}{ NATIONALITY } \\
\hline Italian & 426 & 99.3 \\
\hline Foreign & 3 & 0.7 \\
\hline \multicolumn{3}{|l|}{ SEASON OF ADMISSION } \\
\hline Winter & 137 & 31.9 \\
\hline Spring & 104 & 24.2 \\
\hline Summer & 124 & 28.9 \\
\hline Autumn & 64 & 14.9 \\
\hline \multicolumn{3}{|l|}{ HOUR OF ADMISSION } \\
\hline 8:01am-08:00pm & 358 & 83.4 \\
\hline 08:01pm- 8:00am & 71 & 16.6 \\
\hline \multicolumn{3}{|l|}{ TYPE OF ADMISSION } \\
\hline Urgent & 180 & 41.7 \\
\hline Elective & 249 & 58.3 \\
\hline \multicolumn{3}{|l|}{ DAY OF THE WEEK OF ADMISSION } \\
\hline Monday- Thursday & 300 & 69.9 \\
\hline Friday-Sunday & 129 & 30.1 \\
\hline \multicolumn{3}{|l|}{ DAY OF THE WEEK DAY OF CARE } \\
\hline Monday- Thursday & 319 & 80.6 \\
\hline Friday-Sunday & 83 & 19.4 \\
\hline \multicolumn{3}{|l|}{ WARD } \\
\hline Pediatrics Surgery* & 255 & 59.4 \\
\hline Pediatrics Medicine ${ }^{\wedge}$ & 174 & 40.6 \\
\hline \multicolumn{3}{|l|}{ LENGTH OF STAY (day) } \\
\hline$<5$ & 230 & 53.6 \\
\hline $5-14$ & 153 & 35.7 \\
\hline$>15$ & 46 & 10.7 \\
\hline \multicolumn{3}{|l|}{ TYPE OF DRG } \\
\hline Without inappropriateness risk & 130 & 30.3 \\
\hline With inappropriateness risk & 299 & 69.7 \\
\hline \multicolumn{3}{|l|}{ INAPPROPRIATENESS } \\
\hline Admission & 93 & 21.7 \\
\hline Day of care & 130 & 30.3 \\
\hline
\end{tabular}


Table 2. Inappropriateness of hospital admission and day of stay: univariate analysis

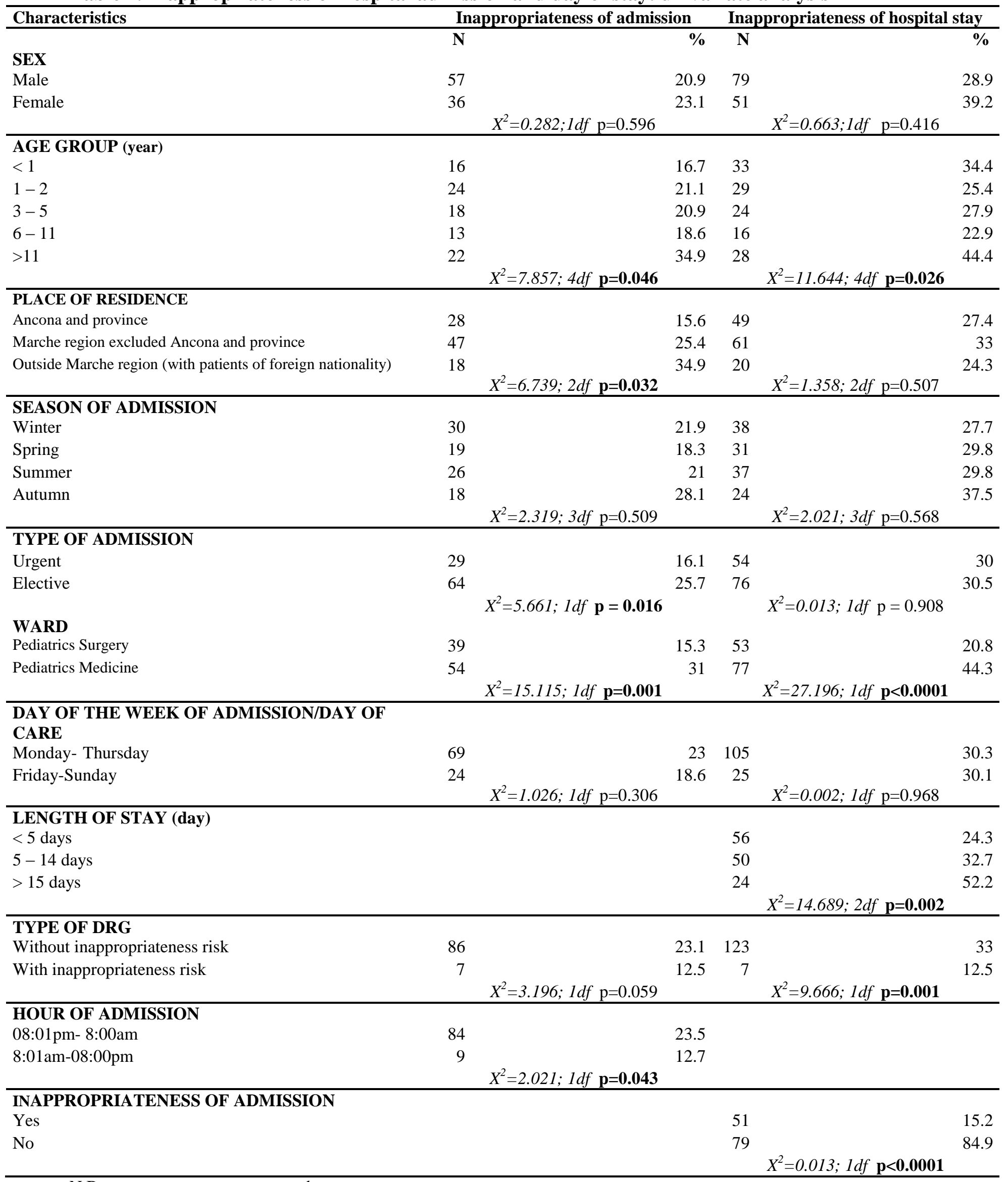

N.B: row percentages are reported. 
Table 3. Logistic regression models results

\begin{tabular}{lrrr}
\hline Variable & OR & $\mathbf{9 5 \%}$ CI & p \\
\hline Model 1. Outcome: Inappropriateness of Admission. & & \\
Log-likelihood: 398.291; chi square: 50.077; $\begin{array}{c}\text { P } \\
\text { TYPE OF ADMISSION }\end{array}$ & 1 & & \\
Urgent & 2.466 & $1.385-4.393$ & $\mathbf{0 . 0 0 2}$ \\
Elective & & & \\
WARD & 1 & & \\
Pediatrics Surgery & 4.014 & $2.331-6.911$ & $<\mathbf{0 . 0 0 0 1}$ \\
Pediatrics Medicine & & & \\
PLACE OF RESIDENCE & 1 & & \\
Ancona and province & 1.894 & $1.188-3.100$ & $\mathbf{0 . 0 1 1}$ \\
Out Ancona and province & & & \\
\hline & & \\
Model 2. Outcome: Inappropriateness of day of stay & & \\
Log-likelihood: 334.731; chi square: 191.575; p $<0.001$ & & \\
\hline WARD & & & \\
Pediatrics Surgery & 1 & & \\
Pediatrics Medicine & 3.037 & $1.735-5.314$ & $<\mathbf{0 . 0 0 0 1}$ \\
TYPE OF DRG & & & \\
With inappropriate risk & 1 & & \\
Without inappropriate risk & 1.489 & $1.076-1.671$ & $\mathbf{0 . 0 0 7}$ \\
LENGTH OF STAY & 1.04 & $1.010-1.072$ & $\mathbf{0 . 0 0 9}$ \\
INAPPROPRIATENESS OF ADMISSION & & & \\
Yes & 1 & & \\
No & 29.226 & $14.863-57.468$ & $<\mathbf{0 . 0 0 0 1}$ \\
\hline
\end{tabular}

